\title{
A new monoclonal antibody against DNA ligase $I$ is a suitable marker of cell proliferation in cultured cell and tissue section samples
}

\author{
B. Vitolo, ${ }^{\S}$ M. R. Lidonnici, C. Montecucco, ${ }^{5}$ A. Montecucco \\ Istituto di Genetica Molecolare, CNR, Pavia, ${ }^{5}$ Cattedra di Reumatologia Università di Pavia, IRCCS \\ Policlinico San Matteo, Pavia, Italy
}

\begin{abstract}
(C)2005, European Journal of Histochemistry
The extensive characterization of the replicative human DNA ligase I (Ligl) undertaken in the last decade demonstrated that the level of this protein strongly correlates with the rate of cell proliferation. This may allow to expand the repertoire of clinical biomarkers for the analysis of cell proliferation. We have produced a new monoclonal antibody (5H5) against Ligl and exploited it as cell proliferation marker in Western blotting and immunofluorescence as well as in immunohistochemistry on paraffin tissue sections. The Western blot analysis showed that the Ligl level detected by $5 \mathrm{H} 5$ antibody is high in all proliferating cells. On the contrary the protein is down regulated in resting human fibroblast and peripheral blood lymphocytes. Immunofluorescence analysis on cultured HeLa cells showed that $5 \mathrm{H} 5$ antibody labels all proliferating cells and displays the same staining pattern of BrdU in S-phase nuclei. Finally the analysis of serial sections of inflamed tonsils and NHL lymph nodes (either frozen or paraffin embedded) demonstrated that $5 \mathrm{H} 5$ marks the same population of cells as the Ki-67 antibody. Our results demonstrate that $5 \mathrm{H} 5$ antibody is a valuable tool for labeling proliferating cells that can be conveniently used in Western blotting, immunocytochemistry and immunohistochemistry.
\end{abstract}

Key words: cell proliferation markers, DNA ligase I, BrdU, Ki-67.

Correspondence: A. Montecucco,

Istituto di Genetica Molecolare CNR,

via Abbiategrasso 207, 27100 Pavia, Italy

Tel: +390382546351.

Fax: +390382 422286

E-mail: montecucco@igm.cnr.it

Paper accepted on July 28, 2005

European Journal of Histochemistry

2005; vol. 49 issue 4 (Oct-Dec): 349-354
$\mathrm{T}$ he analysis of the proliferative kinetics may have a relevant role in characterization of neoplastic disorders and pre-neoplastic lesions in human pathology (Alexandrakis et al., 2004; Broussard et al., 2004; Montecucco et al., 1987; Montecucco et al., 1986; Pich et al., 2004; van Diest et al., 2004). So far, the most used biomarker of cell proliferation is $\mathrm{Ki}-67$ (Abele et al., 1997; Brown and Gatter, 2002; Endl and Gerdes, 2000; Gerdes et al., 1984; Gerdes et al., 1983; Kreipe et al., 1993; Li et al., 2004) although some concerns have emerged from the fact that its function is still unknown. The $\mathrm{Ki}-67$ protein is in some way connected with cell division, as high levels of staining were observed in proliferating tissues, however recent studies have shown that it may be involved in ribosome biosynthesis rather than in cell cycle regulation (MacCallum and Hall, 2000). Furthermore the expression of Ki-67 antigen in cultured cells may be affected by some experimental condition independent of cell proliferation (Baisch and Gerdes, 1987). Therefore additional markers of cell proliferation in neoplastic and pre-neoplastic lesions are desirable.

In eukaryotes, DNA replication occurs in a semidiscontinuous manner, with the lagging strand being synthesized as a series of discrete Okazaki fragments that are first processed and then ligated to form a continuous DNA strand (Kornberg and Baker, 1991). Three distinct DNA ligases encoded by different genes have been identified in mammals (Martin and MacNeill, 2002). Substantial genetic and biochemical evidences indicate that only DNA ligase I is involved in DNA replication being responsible for joining of Okazaki fragments at the replication fork (Timson et al., 2000). Consistent with its role in DNA replication, DNA ligase I expression strongly correlates with the rate of cell proliferation. DNA ligase I activity raises up to 100 times in human lymphocytes upon PHA stimulation and both mRNA and protein level increase after serum 
stimulation of human and mouse primary fibroblasts (Montecucco et al., 1992; Pedrini et al., 1972). On the other hand a strong decrease of DNA ligase I gene expression is produced by confluence, serum starvation and cell differentiation (Camarda et al., 2004; Montecucco et al., 1992). In addition DNA ligase I expression is up-regulated during mouse liver-cell regeneration and in response to mitogenic stimuli (Gariboldi et al., 1995). The distribution of DNA ligase I is highly regulated during the cell cycle and the protein is recruited to the subnuclear sites of ongoing DNA replication (replication factories) during S-phase (Montecucco et al., 1995). The enzyme is phosphorylated in a cell cycle-dependent manner and phosphorylation affects the association of the protein with the replication factories (Ferrari et al., 2003; Rossi et al., 1999). Interestingly both phosphorylation and subnuclear distribution are regulated in response to etoposide, a topoisomerase II inhibitor which affects DNA replication and activates the apoptotic pathway (Montecucco et al., 2001; Rossi et al., 2002).

The aim of the present study is to test the performance of a monoclonal anti-DNA ligase I antibody $(5 \mathrm{H} 5)$ as a marker of cell proliferation in immunofluorescence on cultured cells as well as in immunohistochemistry on paraffin tissue sections in comparison with the Ki-67 antibody.

\section{Materials and Methods}

\section{Antibodies}

$5 \mathrm{H} 5$ monoclonal antibody was developed in collaboration with Areta Interantional by injecting mice with purified recombinant human DNA ligase I overexpressed in a baculovirus/insect cell system as previously described (Ferrari et al., 2003). Anti$\mathrm{Ki}-67$ antigen (mouse monoclonal IgG1, clone $\mathrm{Ki}$ S5) was from DakoCytomation (Glostrup, DK), mouse $I g G_{1}$ isotype control was from RD Systems (Abingdon, UK) and anti- $\alpha$-tubulin monoclonal antibody was from Sigma (St. Luois, Missouri, USA).

\section{Cells}

Cells were grown as monolayer in complete DMEM medium supplemented with $10 \%$ fetal calf serum, $4 \mathrm{mM}$ glutamine and $50 \mu \mathrm{g} / \mathrm{mL}$ gentamicin. All reagents were from Sigma. Cells were grown at $37^{\circ} \mathrm{C}$ in a humidified atmosphere containing $5 \%$
C02 and trypsinized when confluent. To obtain resting cells, confluent human primary fibroblasts were grown for 5 days in DMEM supplemented with $0.25 \%$ fetal calf serum as previously described (Montecucco et al., 1992). Peripheral blood lymphocytes were obtained from healthy donors. Briefly, peripheral blood mononuclear cells (PBMCs) were obtained from $20 \mathrm{ml}$ heparinized blood by Histopaque-1077 density gradient (Sigma) for 45 min and washed with PBS. The pellet was then resuspended in $10 \mathrm{~mL}$ of RPMI 1640 medium, supplemented with $5 \%$ fetal calf serum, 2 $\mathrm{mM}$ glutamine, $100 \mathrm{U} / \mathrm{mL}$ Penicillin-Streptomycin and cultured for $45 \mathrm{~min}$ at $37^{\circ}$ in humidified atmosphere containing $5 \% \mathrm{CO}_{2}$. Non-adherent cells were then centrifuged, washed with PBS and used for western blotting analysis.

The fraction of S-phase cells was determined by counting nuclei incorporating BrdU as described below. S-phase nuclei were $41.5 \%$ in exponentially growing fibroblasts while they dropped to $1.5 \%$ after serum starvation.

\section{Western Blot analysis}

For western blot analysis cells were harvested, washed with PBS, resuspended in $1 \times$ Laemmli sample buffer (Laemmli, 1970) at the concentration of $1 \times 10^{7}$ cells $/ \mathrm{mL}$ and boiled for 10 minutes. Proteins were fractionated on SDS-PAGE and electroblotted to a nitrocellulose transfer membrane (Hybond ECl Nitrocellulose Membrane, Amersham Pharmacia Biotech, UK) with the use of the MiniProtean II (Bio-Rad). Membranes were blocked for Ih with $2 \%$ skim milk (Difco, Detroit, MI) in TBS buffer (20 mM Tris-HCl, pH 7.5, $137 \mathrm{mM} \mathrm{NaCl}$ ) and probed with the primary antibodies diluted in TBS-T buffer (20 mM Tris- $\mathrm{HCl}, \mathrm{pH} 7.5,137 \mathrm{mM}$ $\mathrm{NaCl}$, and $0.1 \%$ Tween-20). Primary antibodies were revealed with horseradish peroxidase-conjugated goat anti-mouse and the enhanced chemiluminescence system (ECL, Amersham, Arlington Heights, IL).

\section{Immunofluorescence microscopy}

Asinchronous HeLa cells grown on coverslip were rinsed with cold PBS, fixed for 4 minutes in cold methanol and incubated for $1 \mathrm{~h}$ at $37^{\circ} \mathrm{C}$ in a humid chamber with the primary antibodies diluted at working concentration (1:1000 for $5 \mathrm{H} 5$ and 1:50 for Ki-S5) in PBS containing $2 \%$ skim milk (Difco). Coverslips were then incubated with the 
TRITC-conjugated anti-mouse IgG (Jackson Immuno Research Lab, UK) secondary antibody for 30 minutes at $37^{\circ} \mathrm{C}$. Nuclei were stained with $0.1 \mu \mathrm{g} / \mathrm{mL} \mathrm{4}{ }^{\prime}, 6$-diamidino-2-phenylindole (DAPI; Sigma). To detect sites of DNA synthesis, cells were grown in $100 \mu \mathrm{M} \mathrm{BrdU}$ (Sigma) for 10 min immediately before methanol fixation and processed as previously described (Montecucco et al., 1995). BrdU was revealed with the Alexa Fluor 488-conjugated anti-BrdU mAb (clone PRB-1, Molecular Probes). Conventional epifluorescence microscopy was performed with an Optical Microscope Olympus IX71 equipped with a $63 \mathrm{X}$ objective connected to a digital camera Cool SNAPES Photometrics. Data acquisition was performed using the MetaMorph software (Universal Imaging Corporation). Confocal microscopy was performed with a Leica TCS SP2 confocal laser microscopy apparatus equipped with a $63 \times / N A=1.32$ oil immersion objective. We used the 488-nm laser line for excitation of Alexa Fluor 488 (detected in a interval between 500-540 nm) and the 543-nm laser line for TRITC fluorescence (detected at $>570 \mathrm{~nm}$ ). Images were exported to Adobe Photoshop (Adobe, San Josè, CA).

\section{Immunohistochemistry}

Immunohistochemistry was performed using antigen retrieval technique on normal and neoplastic lymphoid tissue samples. Tonsil samples were obtained from patients undergoing tonsillectomy; lymphomas tissues were obtained from patients with non-Hodgkin lymphoma (NHL) undergoing biopsy for diagnostic purpose. Tissues were fixed in formalin and processed for paraffin embedding. Serial sections from paraffin-embedded tissue were cut 4-5 $\mu \mathrm{m}$ apart and were collected in glass silanized slides. Tissue sections were deparaffinized and rehydrated through graded ethanol solution. Once hydrated, sections were heated for 30 minutes at $96^{\circ} \mathrm{C}$ in Target Retrieval Solution (DakoCytomation); after 30 minutes of cooling, sections were washed in TBS and incubated for 10 minutes with Protein Block Serum Free (DakoCytomation). Incubation with primary antibodies was performed for 2 hours at room temperature. Primary antibodies used were anti-DNA ligase I 5H5, anti-Ki-67 antigen $\mathrm{Ki}-\mathrm{S} 5$ and mouse $\mathrm{Ig}_{1}$ isotype as a negative control. Sections were then incubated with biotinylated rabbit anti-mouse immunoglobulins (DakoCytomation) (30 minutes) and, after washing with TBS, with streptavidin biotin complex-alkaline phosphatase (Dako-Cytomation) (30 minutes). Sections were then developed using New Fuchsin substrate Kit (DakoCytomation), counterstained with Meyer's Hematoxylin (Sigma) and mounted with Aquamount mounting medium $(B D H$, Switzerland). Sections were then analyzed and photographed using an Optical Microscope Olympus BX51 connected to a digital camera Olympus C3030, data acquisition was performed using Camedia Master 2.0 software.

\section{Labeling Index}

The labeling index with either $\mathrm{Ki}-67$ or $5 \mathrm{H} 5$ antibodies was assessed at $40 \times$ magnification on paraffin embedded samples of NHL lymph nodes. 1500 cells from three different fields were analyized for each tissue section stained with Ki-67. Counting was performed on the same fields on serial sections stained with $5 \mathrm{H} 5$. The results obtained were compared by Student's t-test.

\section{Results}

In HeLa cells extract the monoclonal antibody from $5 \mathrm{H} 5$ clone recognized a single protein corresponding to DNA ligase I. The specificity of binding was also confirmed by the fact that recognition of the epitope in western blotting was entirely competed by an excess of recombinant DNA ligase I (not shown). Western blot analysis of total cell extract from different human proliferating cell lines and from resting fibroblasts and peripheral blood lymphocytes was performed. As shown in Figure 1 the protein level is high in all proliferating cells with a pick of expression in the Burkitt's lymphoma cells (panel A, lane 5) that were those with the highest proliferation rate. On the contrary the protein is undetectable in serum-starved human fibroblast (Figure $1 A$, lane 4) and in peripheral blood lymphocytes (Figure 1B, lane 2).

By immunofluorescence technique we tested the ability of $5 \mathrm{H} 5$ antibody to detect the distribution of DNA ligase I in the different phases of the cell cycle and to label S-phase cells in a population of exponentially growing HeLa cells. As shown in Figure $2 \mathrm{~A}$ replication factories are clearly detectable in HeLa cells stained with $5 \mathrm{H} 5$ antibody (arrowhead) and colocalizes with sites of BrdU incorporation, allowing discriminating S-phase nuclei among proliferating interphase cells based on the immunofluorescence pattern. Exponentially growing cells were 

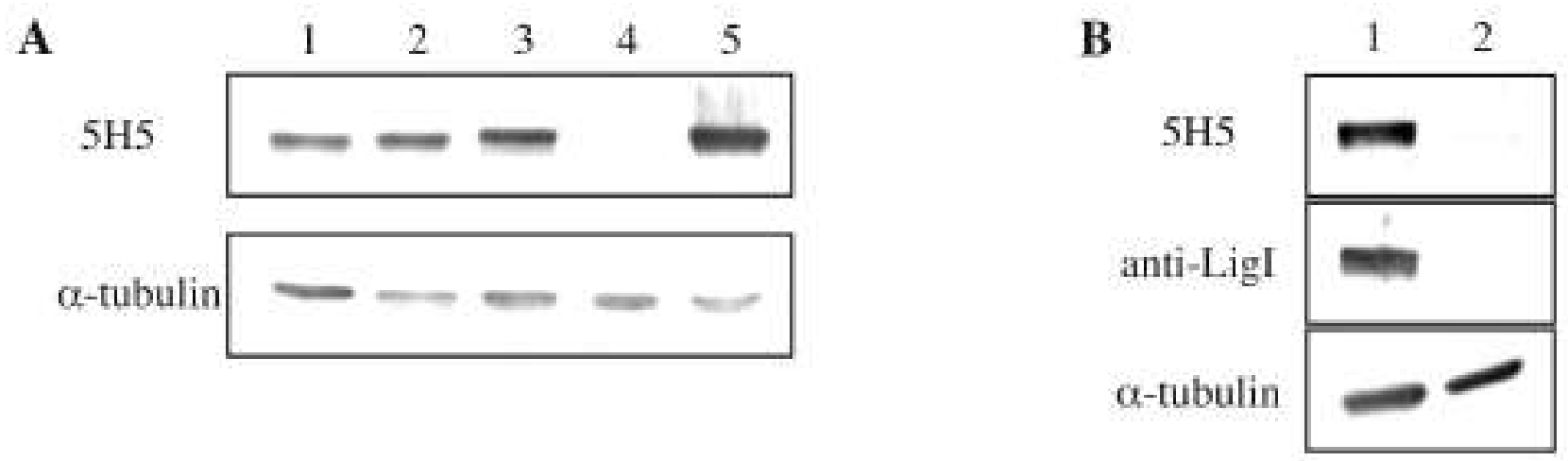

Figure 1. Western blot analysis of total cell extract of different cell lines. (A) lane 1: human epidermoid carcinoma A431 cells; lane 2: Ewing sarcoma cells; lane 3: exponentially growing human fibroblasts; lane 4: resting human fibroblasts; lane 5: Burkitt's lymphoma Raji cells. DNA ligase I was revealed with the 5 H5 monoclonal antibody. (B) lane 1: exponentially growing human lymphoblasts; lane 2: peripheral blood lymphocytes. DNA ligase I was revealed with the $5 \mathrm{H} 5$ monoclonal antibody and with a rabbit polyclonal antiserum (Ferrari et al., 2003). The level of a-tubulin in each sample was shown to compare the amount of cell extract in each lane.

also stained with anti-Ki-67 antibody. As shown in Figure 2B, Ki-67 antibody was not able to discriminate $\mathrm{S}$-phase cells from other interphase cells since it decorates mainly the heterochromatic regions stained by DAPI.

The performance of $5 \mathrm{H} 5$ anti-LigI antibody in the immunohistological detection of proliferating cells was challenged in both paraffin-embedded and frozen tissue sections. Figure 3 shows the analysis of serial sections of paraffin-embedded tonsils with the anti-DNA ligase I (a) and with the anti-Ki-67 (b). The staining pattern was similar indicating that cells labeled with these antibodies belong to the same population. Similar findings were observed on frozen tissue sections (not shown). The same result was obtained comparing the staining pattern of $5 \mathrm{H} 5$ and anti-Ki-67 antibodies on lymph node sections from 3 patients with NHL (Figure $3 \mathrm{c}$ to $\mathrm{f}$ ). Also in these last sections the percentage of positive cells with $\mathrm{Ki}-67$ was almost identical to that obtained with $5 \mathrm{H} 5$ antibody (Table 1 ).

\section{Discussion}

The extensive characterization of the replicative human DNA ligase I undertaken in the last decade demonstrated that the level of the protein strongly correlates with the rate of cell proliferation (Montecucco et al., 1992; Montecucco et al.,

Table 1. Percentage of positive cells (labeling index) for Ki-67 and 5 H5 staining on different sections of involved lymph nodes from 3 patients with non Hodgkin's lymphoma.

\begin{tabular}{|c|c|c|c|c|c|c|}
\hline & & \multicolumn{3}{|c|}{ Fields } & \multirow[t]{2}{*}{ Labeling Index (mean SD) } & \multirow[t]{2}{*}{$p$} \\
\hline & & 1 & 2 & 3 & & \\
\hline \multirow[t]{4}{*}{ Patient 1} & Ki-67+ & $87(17.4 \%)$ & 71 (14.2 \%) & $73(14.6 \%)$ & \multirow{2}{*}{15.41 .744} & \multirow{4}{*}{0.296} \\
\hline & Ki-67- & $413(82.6 \%)$ & $429(85.8 \%)$ & 427 (85.4\%) & & \\
\hline & $5 \mathrm{H} 5+$ & $86(17.2 \%)$ & 92 (18.4\%) & 77 (15.4\%) & \multirow[b]{2}{*}{171.51} & \\
\hline & $5 \mathrm{H} 5-$ & 414 (82.8\%) & 408 (81.6\%) & $423(84.6 \%)$ & & \\
\hline \multirow[t]{4}{*}{ Patient 2} & Ki-67+ & $305(61 \%)$ & $346(69.2 \%)$ & $378(75.6 \%)$ & \multirow{2}{*}{68.67 .318} & \multirow{4}{*}{0.785} \\
\hline & Ki-67- & $195(39 \%)$ & $15430.8 \%)$ & $122(24.4 \%)$ & & \\
\hline & $5 H 5+$ & $276(55.2 \%)$ & $357(71.4 \%)$ & $365(73 \%)$ & \multirow{2}{*}{66.539 .848} & \\
\hline & $5 \mathrm{H} 5-$ & $224(44.8 \%)$ & $143(28.6 \%)$ & $135(27 \%)$ & & \\
\hline \multirow[t]{4}{*}{ Patient 3} & Ki-67+ & $126(25.2 \%)$ & $102(20.4 \%)$ & $114(22.8 \%)$ & \multirow{2}{*}{22.82 .4} & \multirow{4}{*}{0.759} \\
\hline & Ki-67- & $374(74.8 \%)$ & $398(79.6 \%)$ & $386(77.2 \%)$ & & \\
\hline & $5 \mathrm{H} 5+$ & $137(27.4 \%)$ & $95(19 \%)$ & $124(24.8 \%)$ & \multirow{2}{*}{23.734 .3} & \\
\hline & $5 \mathrm{H} 5-$ & 363 (72.6\%) & $405(81 \%)$ & 376 (75.2\%) & & \\
\hline
\end{tabular}



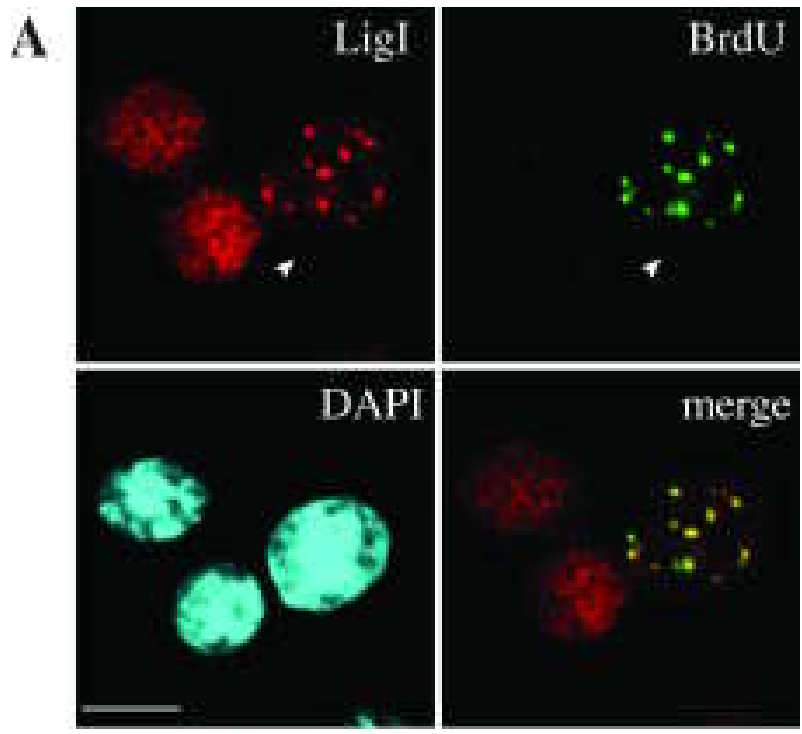

B
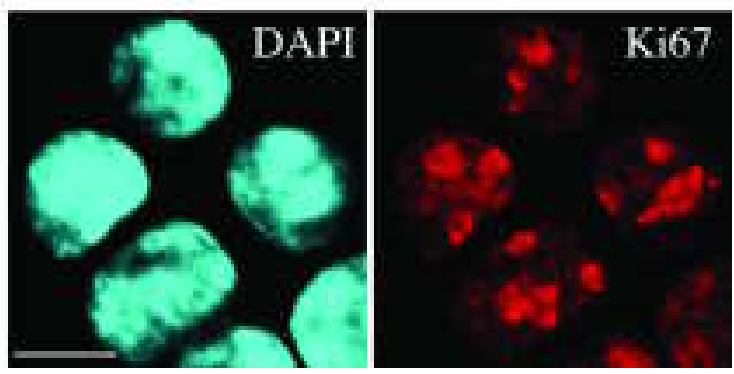

Figure 2. Immunolocalization of DNA ligase I and Ki-67 antigen in HeLa cells. (A) Exponentially growing HeLa cells were pulse labelled with BrdU before fixation and stained with anti-DNA ligase I 5H5 monoclonal antibody (Ligl) or with the anti-BrdU Alexa Fluor 488-conjugated antibody (green). 5 H5 antibody was revealed with a TRITC-conjugated anti-mouse secondary antibody (red). Nuclei were stained with DAPI. The arrowhead points to a nucleus showing late-S phase replication factories. The yellow spots after overlay of $5 \mathrm{H} 5$ and BrdU images (merge) indicate the extent of colocalization between DNA ligase I and newly synthesized DNA. (B) Exponentially growing HeLa cells were fixed and stained with anti-Ki-67 monoclonal antibody and with a TRITC-conjugated anti-mouse secondary antibody. Nuclei were stained with DAPI. Bar: $10 \mu \mathrm{m}$.

1995; Timson et al., 2000). Therefore we have investigated the possibility to use a new anti-DNA ligase I antibody (5H5) to detect proliferating cells.

By immunofluorescence studies on exponentially growing HeLa cells we have found that $5 \mathrm{H} 5$ antibody labels all proliferating cells as $\mathrm{Ki}-67$, and also allows to identify S-phase cells as the immunolabeling distribution fully resembles BrdU incorporation. In fact, in S-phase nuclei DNA replication takes place in dynamic functional compartments referred to as replication factories where replicative factors and newly synthesized DNA accumulate (Hozak et al., 1993). DNA ligase I is recruited to replication factories via a specific interaction with
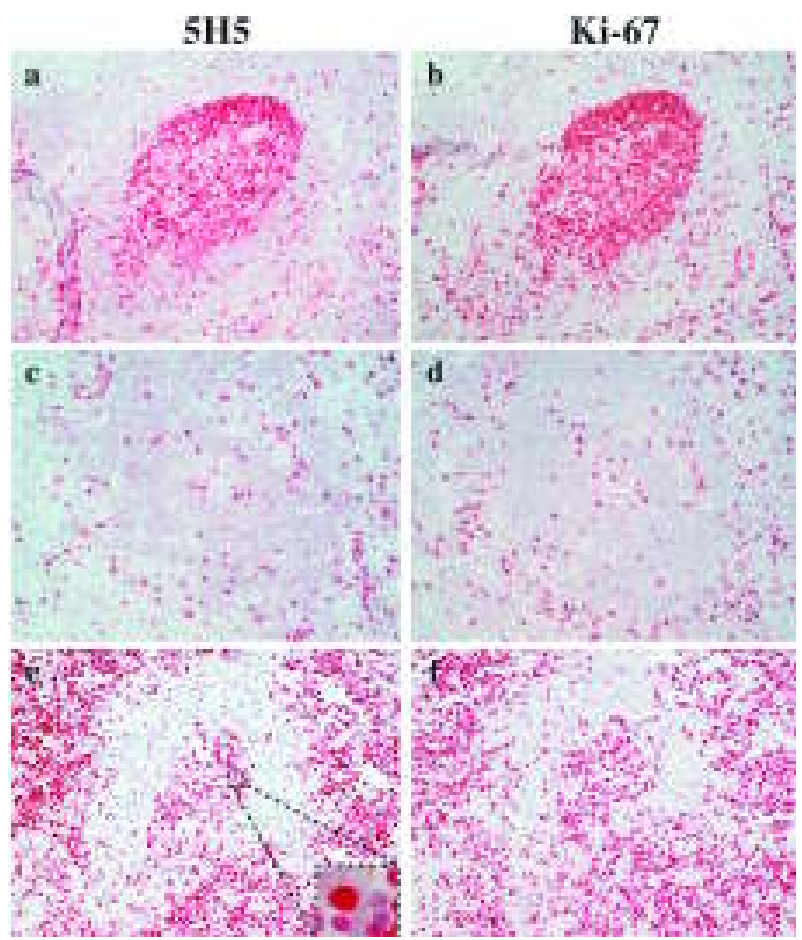

Figure 3. Immunohistochemistry on formalin-fixed paraffinembedded tissues for anti-DNA ligase I (5H5) and anti-Ki-67. Staining was performed on serial sections of tonsils (a and b) and of non-Hodgkin lymphomas lymph nodes (c, $d$ and $e, f)$. The original magnification was $20 X$ for all panels and $100 X$ for the inset of panel e showing the nuclear pattern of $5 \mathrm{H} 5$ staining.

proliferating cell nuclear antigen and colocalizes with sites of BrdU incorporation throughout Sphase (Montecucco et al., 1998) showing a characteristic punctate pattern of staining. On the contrary in G1 and G2 phases the protein is homogeneously distributed throughout the nucleoplasm and in mitosis it dissociates from chromatin and spreads in the whole cell body (Montecucco et al., 1995).

Formalin-fixed paraffin-embedded tissues are widely used in clinical pathology for in situ analysis of the rate of cell proliferation as this technique allows preservation of the morphology and the possibility of maintaining the specimens for a long time. Therefore we compared the ability of $5 \mathrm{H} 5$ and anti-Ki-67 antibodies to selectively label proliferating cell on serial sections from lymphoid tissues. Our results demonstrate that the two antibodies mark the same population of cells either in inflamed tonsils or in NHL lymph nodes. This indicates that $5 \mathrm{H} 5$ antibody can be conveniently used for in situ immunohistological techniques on paraffin tissue sections to detect proliferating cells. In 
some instances, distinct nuclear speckles could be found in formalin embedded samples stained with $5 \mathrm{H} 5$ (see Figure $3 \mathrm{e}$, inset), however a clear cut differentiation of S-phase cells from other proliferating cells does not appear feasible in this setting.

In conclusion since the human antigen recognized by $5 \mathrm{H} 5$ clone, i.e. DNA ligase I, has a well-known function and has been extensively characterized, the indexes obtained with this antibody can be specifically related to the proliferative activity of analyzed cells. Accordingly, we believe that $5 \mathrm{H} 5$ monoclonal antibody is a promising tool for labeling proliferating cells in cell research as well as in clinical pathology as it can be conveniently used in western blotting, immunocytochemistry and immunohistochemistry.

\section{Acknowledgements}

The authors thank the Immunolocalization Service of IGM and the Centro Grandi Strumenti, University of Pavia for confocal microscopy facilities. This work was supported by a grant from Fondazione CARIPLO (Rif. 2003.1663/10.8441) to A.M.

\section{References}

Abele M, Valente G, Kerim S, Navone R, Onesti P, Chiusa L, et al. Significance of cell proliferation index in assessing histological prognostic categorties in Hodgkin's disease. A immunohistochemical study with Ki-67 and MIB-1 monoclonal antibodies. Haematologica 1997; 82: 281-5.

Alexandrakis M, Passam F, Kyriakou D, Dambaki K, Niniraki M and Stathopoulus E. Proliferation index correlation with prognostic parameters and outcome in multiple myeloma. Am J Clin Oncol 2004; 27: 8-13.

Baisch H, Gerdes J. Simultaneous staining of exponentially growing versus plateau phase cells with the proliferation-associated antibody $\mathrm{Ki}-67$ and propidium iodide: analysis by flow cytometry. Cell Tissue Kinet 1987; 20: 387-91.

Broussard J, Tan P and Epstein J. Atypia in inverted urothelial papillomas: pathology and prognostic significance. Hum Pathol 2004; 35: 1499-504.

Brown D, Gatter K. Ki67 protein: the immaculate deception? Histopathology 2002; 40: 2-11.

Camarda G, Siepi F, Pajalunga D, Bernardini C, Rossi R, Montecucco $A$, et al. A pRb-independent mechanism preserves the postmitotic state in terminally differentiated skeletal muscle cells. J Cell Biol 2004; 167: 417-23.

Endl E, Gerdes J.The Ki-67 protein: fascinating forms and an unknown function. Exp Cell Res 2000; 257: 231-7.

Ferrari G, Rossi R, Arosio D, Vindigni A, Biamonti G, Montecucco A. Cell cycle-dependent phosphorylation of human DNA ligase I at the cyclin-dependent kinase sites. J Biol Chem 2003; 278: 37761-7.

Gariboldi M, Montecucco A, Columbano A, Ledda-Columbano G, Savini E, Mananti G, et al. Genetic mapping and expression analysis of the murine DNA ligase I gene. Molecular Carcinogenesis 1995; 14: 71-4.

Gerdes J, Lemke H, Baisch H, Wacker H, Schwab U, Stein H. Cell cycle analysis of a proliferation-associated human nuclear antigen defined by the monoclonal antibody Ki-67. J Immunol 1984; 133: 1710-15.

Gerdes J, Schwab U, Lemke H, Stein H. Production of a mouse monoclonal antibody reactive with a human nuclear antigen associated with cell proliferation. Int J Cancer 1983; 31: 13-20.

Hozak P, Hassan AB, Jackson DA and Cook PR. Visualization of replication factories attached to a nucleoskeleton. Cell 1993; 73: 36173.

Kornberg A, Baker TA (eds.). DNA Replication. Freeman, W., H., and Company, New York, 1991.

Kreipe $H$, Wacker $H$, Heidebrecht $H$, Haas K, Hauberg M, Tiemann M, et al. Determination of the growth fraction in non-Hodgkin's lymphomas by monoclonal antibody Ki-S5 directed against a formalinresistant epitope of the $\mathrm{Ki}-67$ antigen. Am J Pathol 1993; 142: 1689-94.

Laemmli UK. Cleavage of structural proteins during the assembly of the head of bacteriophage T4. Nature 1970; 227: 680-5.

Li H, Byeon I-J, Ju Y and Tsai M-D. Structure of the human Ki67 FHA domain and its binding to a phosphoprotein fragment from hINFK reveal unique recognition sites and new views to the structural basis of a FHA domain function. J Mol Biol 2004; 335: 371-81.

MacCallum D, Hall P. The location of pKi67 in the outher dense fibrillary compartments of the nucleolus points to a role in ribosome biogenesis during cell division cycle. J Pathol 2000; 190: 537-44.

Martin I, MacNeill S. ATP-dependent DNA ligases. Genome Biol 2002: 3005.1-05.7.

Montecucco A, Biamonti G, Savini E, Focher F, Spadari S, Ciarrocchi $\mathrm{G}$. DNA Ligase I gene expression during differentiation and cell proliferation. Nucleic Acids Res. 1992; 20: 6209-14.

Montecucco A, Rossi R, Ferrari G, Scovassi AI, Prosperi E, Biamonti $G$. Etoposide induces the dispersal of DNA ligase I from replication factories. Mol Biol Cell 2001; 12: 2109-18.

Montecucco A, Rossi R, Levin DS, Gary R, Park MS, Motycka TA, et al. DNA ligase I is recruited to sites of DNA replication by an interaction with proliferating cell nuclear antigen: identification of a common targeting mechanism for the assembly of replication factories. EMBO J. 1998; 17: 3786-95.

Montecucco A, Savini E, Weighardt F, Rossi R, Ciarrocchi G, Villa A, et al. The N-terminal domain of human DNA ligase I contains the nuclear localisation signal and directs the enzyme to sites of DNA replication. EMBO J. 1995; 14: 5379-86.

Montecucco C, Riccardi A and Ascari E. Bone marrow cell kinetics in primary myelodysplastic syndromes. Haematologica $1987 ; 72$ (6 Suppl): 132-4.

Montecucco C, Riccardi A, Ucci G, Danova M, Carnevale R, Caporali $\mathrm{R}$, et al. Analysis of human myeloma cell population kinetics. Acta Haematol 1986; 75: 153-6.

Pedrini A, Nuzzo F, Ciarrocchi G, Dalprà $L$ and Falaschi A. Induction of polynucleotide ligase in human lymphocytes stimulated by phytohemoagglutinin. Biochem. Biophys. Res. Commun. 1972; 47: 1221-7.

Pich A, Chiusa $L$ and Navone R. Prognostic relevance of cell proliferation in haed and neck tumors. Ann Oncol 2004; 15: 1319-29.

Rossi R, Montecucco A, Donzelli M, Denegri M, Biamonti G and Scovassi AI. DNA ligase I is dephosphorylated during the execution step of etoposide-induced apoptosis. Cell Death Diff 2002; 9: 89-90.

Rossi R, Villa A, Negri C, Scovassi I, Ciarrocchi G, Biamonti G, et al. The replication factory targeting sequence/PCNA-binding site is required in $\mathrm{G}(1)$ to control the phosphorylation status of DNA ligase I. EMBO J 1999; 18: 5745-54.

Timson DJ, Singleton MR, Wigley DB. DNA ligases in the repair and replication of DNA. Mutat Res 2000; 460: 301-18.

van Diest $P$, van der Wall $E$, Baak J. Prognostic value of proliferation in invasive breast cancer: a review. J Clin Pathol 2004; 57: 675-81. 